\title{
Structure of Neurological Departments in Germany: Results of the 12th Survey by the German Neurological Society
}

\section{(ㄷ) (2) (ㅇ)}

Authors

Michael Schroeter ${ }^{1}$, Frank Erbguth ${ }^{2}$, Reinhard Kiefer ${ }^{3}$, Tobias Neumann-Haefelin ${ }^{4}$, Christoph Redecker ${ }^{5}$, Helmuth H. Steinmetz ${ }^{6}$, Rainer Riedel ${ }^{7}$, Gereon R. Fink ${ }^{1}$

On behalf of the committee „Benchmarking \& Quality Management“, German Neurological Society (Deutsche Gesellschaft für Neurologie)

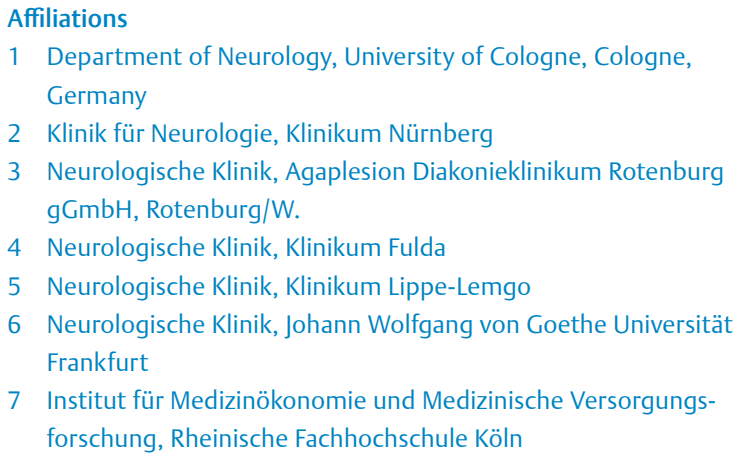

1 Department of Neurology, University of Cologne, Cologne, Germany

2 Klinik für Neurologie, Klinikum Nürnberg

3 Neurologische Klinik, Agaplesion Diakonieklinikum Rotenburg $\mathrm{gGmbH}$, Rotenburg/W.

4 Neurologische Klinik, Klinikum Fulda

5 Neurologische Klinik, Klinikum Lippe-Lemgo

6 Neurologische Klinik, Johann Wolfgang von Goethe Universität Frankfurt

7 Institut für Medizinökonomie und Medizinische Versorgungsforschung, Rheinische Fachhochschule Köln

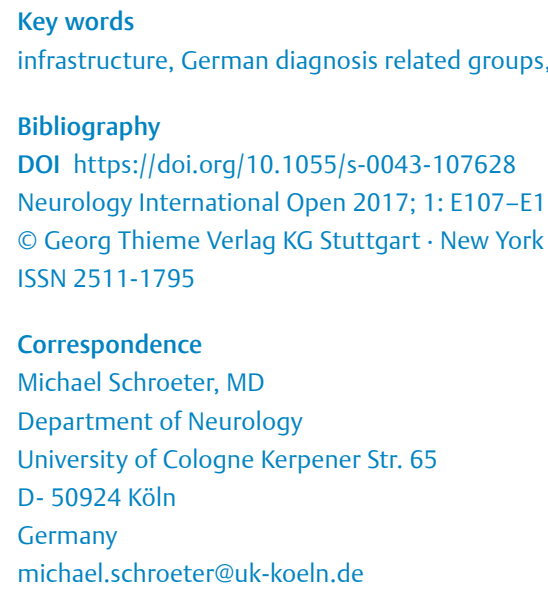

\begin{abstract}
The German Neurological Society has conducted a survey of the structure of neurological in-patient care every other year. The present survey covers the year 2015 . With a response rate of $62 \%$ in mind, the questionnaire allowed meaningful comparisons to former surveys covering the years 2013 and 2011.

Only a minority of departments maintains intensive care units of their own. In contrast, 24/7 presence of neurological physicians has become standard in interdisciplinary emergency rooms. Stroke management has made neurology increasingly involved in emergency care. Since 2015, thrombectomy has been recognized as state-of-the-art therapy for a subgroup of stroke patients, raising special demands for the availability of CT and MRI on a 24/7 basis. However, infrastructure did not improve as compared to former surveys.

Number of beds, total procedures and average procedures per case proceeds (case mix, case mix index) has remained roughly unchanged. However, case numbers increased, and average length of stay robustly decreased within 2 years by $17 \%$ to 5.4 days.

Staff structures were heterogeneous and were involved in various duties apart from inpatient care covered by the German Diagnosis-Related Groups (DRG) system. Departments did not succeed in differentiating expenditures related to the DRG system from other procedures. Shortage of nursing staff forced $22 \%$ of departments to temporally reduce services, $6 \%$ of departments did so because of a shortage of physicians, and in $2 \%$ of departments, both occurred. Departments were confident of certifications as means of quality management, and a few suggestions were provided for more meaningful parameters for outcome-oriented quality management in the future.
\end{abstract}

\section{Introduction}

Every other year since 1980, the German Neurological Society (Deutsche Gesellschaft für Neurologie - DGN) has conducted a survey of German hospitals providing acute neurological care in order to obtain information regarding neurological inpatient care. The results of the preliminary surveys have been published in the journal Aktuelle Neurologie (Current Neurology) and provide a source-independent freely-accessible data source for benchmark orientation, thus supporting strategic decision-making in hospitals [1-5]. Based on the update and development of the preliminary surveys, we can now report on the survey conducted in 2016 for reporting year 2015. When we updated the questionnaire, priority was given to the continuity of questions in order to ensure comparability of the answers to the preliminary surveys and thus support statements on trends at the hospitals. The preliminary surveys revealed a considerable heterogeneity of the data, in particular with regard to staffing. It was discussed that different involvement beyond the purview of the DRG could explain these differences. For this reason, the current survey for the first time also queried regarding the proportion of revenues generated outside the DRG area. This should be used as an estimator for DRG-independent resource sharing, so that, e. g., shared personnel for the non-DRG 
area can be separated from the total personnel key. The hope was to achieve better data homogeneity and thereby increase the validity and meaningfulness of the data. Finally, the survey continues with parameters that can be used to measure results-oriented quality in the hospitals. These should be suitable to identify possible negative effects and incentives of the DRG system, e. g., by reducing the length of stay in a measurable manner.

\section{Methods}

This survey was sent to all neurological hospitals maintaining beds which calculate full-hospital acute treatment according to the DRG system.

Beyond the changes to the preliminary survey in 2014, there was only one new question regarding the percentage of revenues generated outside the DRG purview. $\$ Fig. 1 shows the questionnaire in a translated version. The survey of the 2015 data year was first sent out in April 2016 to 348 clinics (12 more than in the preliminary survey). 4 further mailings followed by surface mail and e-mail, once again to all hospitals, then 3 times to hospitals which had not yet answered, one of which was sent by the DGN office. With the exception of 6 surveys (see below) all of the questionnaires (returned as of November 1, 2016) were included in the analysis. Responses were received from 218 hospitals (of which 4 were in several versions returned in multiple parts). The data of 6 hospitals demonstrated pervasive inconsistencies; according to their internet presence, they are operated by a single, dominant organizational unit (4 hospitals), one geriatric facility with rehabilitation (one hospital), as well as a specialized weaning facility (one hospital). We decided not to include these data in the greater analysis; therefore our reports concerns a sample of 212/342 hospitals (62\%).

The survey instructions explicitly emphasized the option of leaving questions open if no reliable information could be given; consequently we frequently received incomplete questionnaires. In several places the requested data provided either direct or indirect references to verify data consistency. Inconsistent responses were not included in the assessment.

For these reasons, the number of evaluated responses is heterogeneous with respect to some questions and may differs considerably throughout the analyzes below.

The evaluation and graphical representation was largely performed using Microsoft Excel. The results resemble a random sample, the normal distribution of which we could not determine. Accordingly, we restricted ourselves to descriptive statistics indicating median, upper and lower quartile, as well as the range. We will dispense with stating the arithmetical mean value and standard deviation.

\section{Results}

The response rate among the 35 university-related hospitals with $66 \%$ was just above the general $62 \%$ rate of response (218/342). The overall response rate was in the range of preliminary surveys in 2013 (66\%), 2011 (58\%) and 2009 (63\%).

With respect to total beds in all hospitals, a median of 56 beds was identical to the results of 2013 , with lower (25\%) quartile limits for 44 beds (i. e., $25 \%$ of the hospitals had 44 beds maximum) and the upper (75\%) quartile 71 beds (i. e., $25 \%$ had more than 71 beds). The median and the quartiles in the group of university hospitals also differed only minimally from the data from 2013 and 2011, but were higher on average (median 72 beds, 1st quartile 61 beds, 3rd quartile 91 beds). With a single exception, all hospitals reporting numbers of beds offered specialized beds for stroke patients ( 2 responses were illegible, however). The median was 8 beds, (2011: 6 beds, unchanged in 2013, the quartiles remained unchanged from 2013 with 6 and 11 beds). Likewise, university hospitals tended to provide greater numbers (median: 14 beds).

Of the hospitals responding, 106 of 212 had 2 or more intensive care beds. Thus the ratio of neurological hospitals/hospitals with ICU fell significantly from $86 \%$ to $50 \%$. Possibly the number was even lower. It is assumed that a portion of the respondents indicated the total number of existing beds, including interdisciplinary ICU beds, or beds reserved for rehabilitative (weaning) purposes. Some facilities apparently included their stroke beds among the intensive care beds, making an individual distinction even more difficult. Likewise, at university hospitals ICU beds have not been at neurologist' command and the number of beds varied widely from 4-27 beds. The availability of pre-rehab beds in university hospitals was the exception (4/23); in the acute-care hospitals, the spectrum is more heterogeneous, and without a clearly-defined cut-off point, can also include a rehabilitation facility with a small acute-care unit (see above).

The inclusion of neurology in interdisciplinary emergency rooms ( $82 \%$ ), of which requiring a $24 / 7$ presence of neurological physicians $(78 \%)$ has been confirmed, each being a few percentage points higher than in 2013.

The more neurology becomes a part of emergency services, the more urgent it becomes to make available suitable diagnostic infrastructure around the clock. The MR CLEAN study has been published in 2015, indicating that in the reporting year there was class 1 evidence for the need for thrombectomy. Thus, there was the medical necessity to provide adequate diagnostics for appropriate patients within a narrow time window. Only 140/212 hospitals confirmed around-the-clock availability of an MRI, and 6 hospitals did not have the possibility of performing MRI or CT at all times. However, all these facilities maintained stroke units.

It was interesting that $118 / 212$ (56\%) of the hospitals indicated the possibility of thrombectomy around the clock. Unfortunately it was not clear whether these were performed in-house or were performed in cooperation with a larger center.

12 hospitals did not offer around-the-clock CSF diagnosis. \ Fig. 2 illustrates trends with respect to infrastructural facilities compared to 2011 and 2013, and shows that contrary to medical necessity, clinical infrastructural facilities have declined.

In addition to inpatient acute care, hospitals are assuming numerous outpatient-related tasks. Compared to 2 years ago, significantly more outpatient structures, several in the majority of cases, are in place ( $\vee$ Fig. 3 ). To an increasing extent, these structures are taking up time and personnel resources. Therefore, for the first time we inquired regarding the percentage of revenues generated outside the DRG purview. Mostly this amount was apparently estimated. Only 136 hospitals (64\%) provided an amount. Remarkably, 21 hospitals reported no revenues outside the DRG area, although 8 of them also maintained outpatient structures or consultants apart from pre- and post-release care allowed under the DRG system. A further 76 hospitals reported a revenue share of less than 
Name, address of the department:

1. Number of beds

total __ Stroke Unit __ ICU ___ early rehab___ $\square$ interdisciplinary

2. Outpatient facilities (multiple items may apply)

Day hospital/unit

Outpatient facilities according to German law as follows:

$\square$ Poliklinik $\square$ Ermächtigung $\square \S 116 b \quad \square$ Praxis im Krhs. $\square$ MVZ

$\square$ pre/post treatment for inhouse patients

How many \% of your department's total proceeds are generated outside of G-DRGs? $\%$

3. Emergency room (ER) and consultancy

$\square$ Neurological ER $\square$ interdisciplinary ER $\square$ both/other

Neurological emergencies are covered by

$\square$ consultancy/on call $\square$ 24/7 presence

numbers of emergency patients

numbers of consultations in house

varies

percentage of emergency admissions

numbers of consultations in other facilities

4. ICU

$\square$ Neurology heads ICU $\square$ ICU headed by others

5. Availability of infrastructure \& facilities

CT 24/7

MRI 24/7

CT- or MR-angiography $24 / 7$

Thrombectomy/intervention 24/7

Radiologist on duty

CSF analysis 24/7

$\square$ no
$\square$ no
$\square$ no
$\square$ no
$\square$ no/telemedicine
$\square$ no

case admissions:

Stroke Unit-cases

Casemix-Index (per case proceeds) ____ length of stay

outpatient cases

7. Allocation of proceeds

a) internal referrals ...

$\square$ as of admission

b) for ICU cases

$\square$ as of dismissal

according to length of stay

other (please, specify)

$\square$ to the dept.

to other depts.

ICU is a separate business unit

• Fig. 1 Questionnaire for reporting year 2015.

$10 \%, 35$ hospitals stated between 10 and $50 \%$, and one hospital reported $98 \%$. If these reported percentages are used to determine the proportion of personnel dedicated to the G-DRG system, then the heterogeneity of the data further rissed: the difference between the first and third quartile for the benchmark "Case mix / physician" in the group of these 136 hospitals increased. The hypothesis formulated during the planning of the survey, that the heterogeneity of staffing was influenced by a varying commitment of the hospitals in the non-DRG area, could not be confirmed.

Number of cases, case mix and case mix index (CMI) are the 3 global parameters used to assess the performance of hospitals and to best compare them to one another. They are also considered "measures of effectivity" (see below). > Table 1 compares the related medians for 2011 and 2013 and provides the range and quar- 
Questionnaire - page 2

8a. TOP 5 G-DRG, case numbers

\begin{tabular}{|l|l|}
\hline G-DRG & numbers \\
\hline & \\
\hline & \\
\hline & \\
\hline & \\
\hline
\end{tabular}

8b. Procedures combination therapy

\begin{tabular}{|l|l|}
\hline OPS catalogue & numbers \\
\hline $8-981.0$ (acute stroke treatment $>24 \mathrm{~h},<72 \mathrm{~h})$ & \\
\hline $8-981.1$ (acute stroke treatment $>72 \mathrm{~h}$ ) & \\
\hline
\end{tabular}

Which combination therapies do you perform on a regular basis?

9. Human ressources
a) Staff numbers head(s)
consultants
residents
residents on ICU
percentage of vacant positions
, maternity/parental leave (numbers)
b) Staff structures (numbers):
with approved speciality (Fachärzte)
gender ratio
(f)/
(m)
part-time staff honorary staff

\section{c) Staff shortage?}
Did any staff shortage cause limitation or reduction of patient care?
$\square$ no $\square$ yes, shortage of physicians $\square$ yes, shortage of nursing personnel

working in shift duties

\section{Doctor's duties}
consultant $\square$ on call
$\square$ present in hospital
$\square$ present in hospital
$\square$ shift duties
residents $\square$ on call
$\square$ shift duties (multiple may apply)
The head of department takes part
$\square$ duties in hospital
$\square$ background/on call
$\square$ does not take part

11. Certifications

a) Did your (entire) department underwent certification procedures? $\square$ no $\square$ yes

b) Certification of sections (e.g. Stroke Unit)? $\square$ no $\square$ yes, that is

c) if „yes“ in a) or b): Did you evaluate effects of the certification process?

$\square$ no $\square$ yes (please, specifiy)

Personally, I think that the certification process ...

$\square$ improved a lot ... $\square$ did not essentially improve ... $\square$ did not improve at all ...

the quality of patient care in my department.

\section{Quality management and quality of care}

To assess quality and outcome-oriented quality of patient care in Neurological department I suggest the following parameter(s)

Fig. 1 (Continued). 


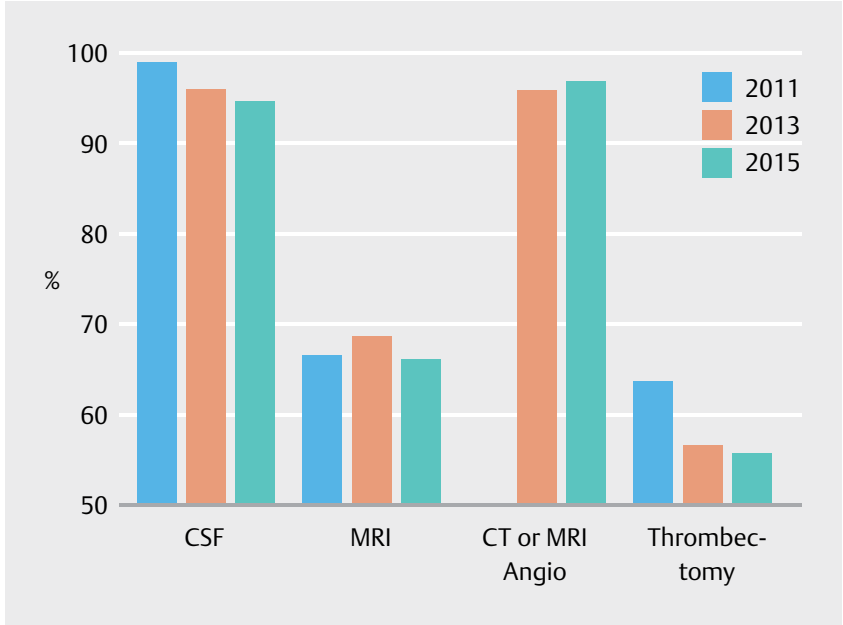

- Fig. 2 Infrastructural deficits for acute neurological care. One-hundred percent around-the-clock availability would be required to provide guideline-oriented and evidence-based care of neurological emergencies. Since 2011 the situation has not improved, but has tended to become worse.

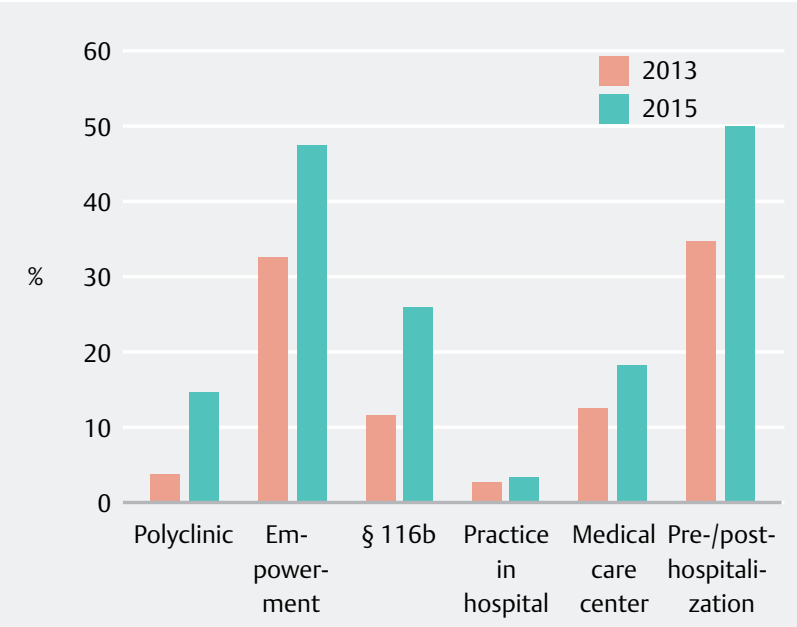

- Fig. 3 Availability of outpatient as determined by German law. Percent of responding hospitals (multiple instances as a rule) in reporting years 2013 and 2015.

- Table 1 Essential performance data comparing 2011, 2013 and 2015.

\begin{tabular}{|c|c|c|c|c|c|c|}
\hline & $\begin{array}{l}\text { Median } \\
2011\end{array}$ & $\begin{array}{l}\text { Median } \\
2013\end{array}$ & $\begin{array}{l}\text { Median } \\
2015\end{array}$ & Range & $\begin{array}{l}\text { Lower } \\
\text { quartile }\end{array}$ & $\begin{array}{l}\text { Upper } \\
\text { quartile }\end{array}$ \\
\hline Fully-inpatient cases [n] & 2383 & 2408 & 2525 & $313-8000$ & 1979 & 3200 \\
\hline Of which: stroke unit cases & 729 & 750 & 826 & $25-4100$ & 621 & 1128 \\
\hline Outpatient or emergency & 1200 & 1200 & 1028 & $20-11000$ & 401 & 2844 \\
\hline Emergency contacts & 1800 & 2109 & 1954 & $10-11000$ & 969 & 3000 \\
\hline Case mix & 2443 & 2526 & 2713 & $361-7072$ & 1807 & 3560 \\
\hline Case Mix Index & 1.04 & 1.03 & 1.08 & $0.78-1.70$ & 1.01 & 1.23 \\
\hline Average hospitalization time [days] & 6.8 & 6.5 & 5.4 & $4.0-8.8$ & 4.5 & 6.0 \\
\hline Case mix/Bed/Day & 0.12 & 0.13 & 0.13 & $0.02-0.33$ & 0.11 & 0.15 \\
\hline Fulltime physician staff & 15 & 15 & 16 & $4-69$ & 12 & 21 \\
\hline Case mix points/Physician/Year & 163 & 159 & 153 & $23-395$ & 126 & 186 \\
\hline
\end{tabular}

For 2015 range as well as limits of the upper and lower quartiles are also given

tile limits for the first and third quartile for the current reporting year.

With an average hospitalization time of 5.4 days, more than 2500 cases per year and hospital have been treated, including over 800 cases on the stroke unit. Consequently, the trend of previous years, namely to handle more and more cases in an ever shorter period, has not only continued, but has also accelerated further. While the median number of cases increased by 25 cases ( $+1 \%$ ) from 2011-2013, it rose by $5 \%$ from 2013-2015; the stroke case rate increased by $4 \%$ from 2011-2013, and by $10 \%$ from $2013-$ 2015. At the same time, hospitalization time decreased by $4 \%$ between 2011 and 2013, but by a drastic 14\% from 2013-2015 (see > Fig. 4). The case mix grew more moderately than the number of cases, and the CMI likewise decreased slightly. The CMI showed a moderate correlation to the number of available stroke unit beds ( $>$ Fig. 5). With one exception, only hospitals also offering intensive care beds went beyond a CMI limit value of about 1.22.

DRG B70 stroke was by far the most frequently reported DRG diagnosis among the TOP 3 DRG cases. It is coded twice as much as a TIA (B69) both together twice as frequently as the totality of all other neurological DRG diagnoses in the TOP 3.

We were able to extract data from 162 questionnaires on combination treatment of acute stroke cases (OPS code 8-981.x). Combination treatment was performed 114,041 times in these hospitals, of which code 8.981.0 was performed 60321 times (combination treatment $>24 \mathrm{~h}$, less than $72 \mathrm{~h}$ ) and code 8-981.1 was carried out 53,720 times (combination treatment $>72 \mathrm{~h}$ ). Thus the ratio of both OPS codes was 53:47, with the shorter variant of combination treatment slightly predominating. 


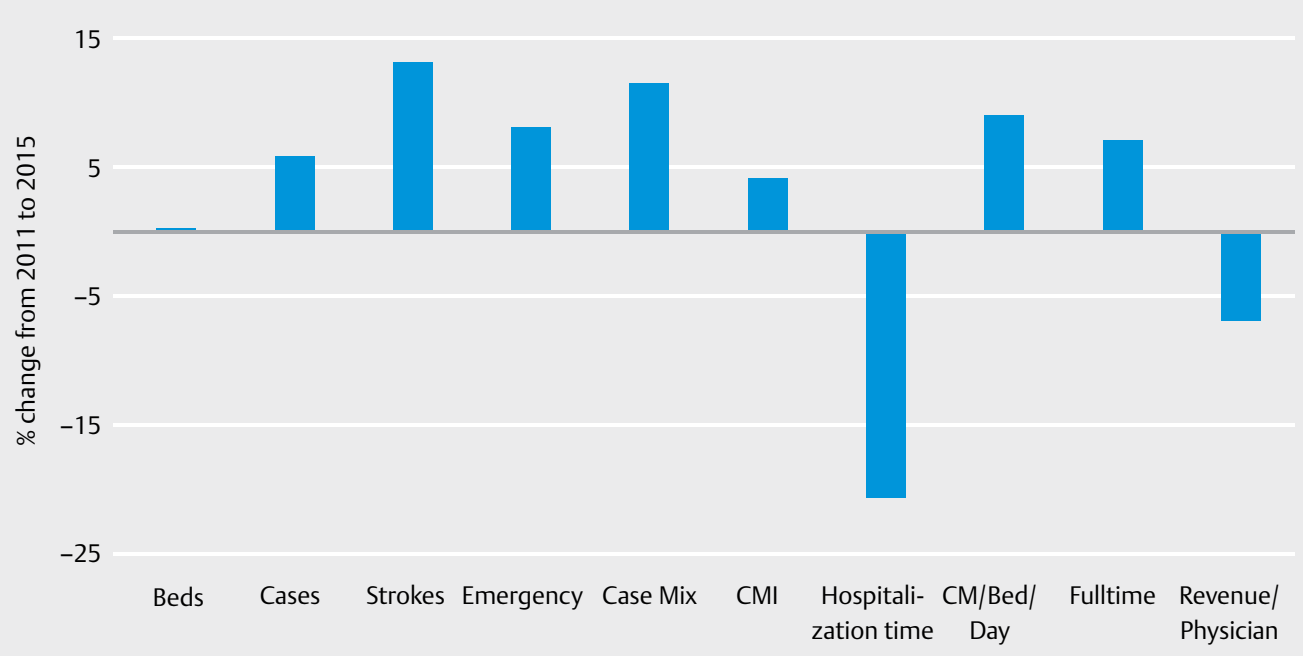

- Fig. 4 Economic benchmark fig.s between 2011 and 2015. An increase in case mix and case mix index is the result of a rapid decline of hospitalization time and increase of cases, particularly stroke cases. Revenues per physician declined with a slight increase of full-time physicians.

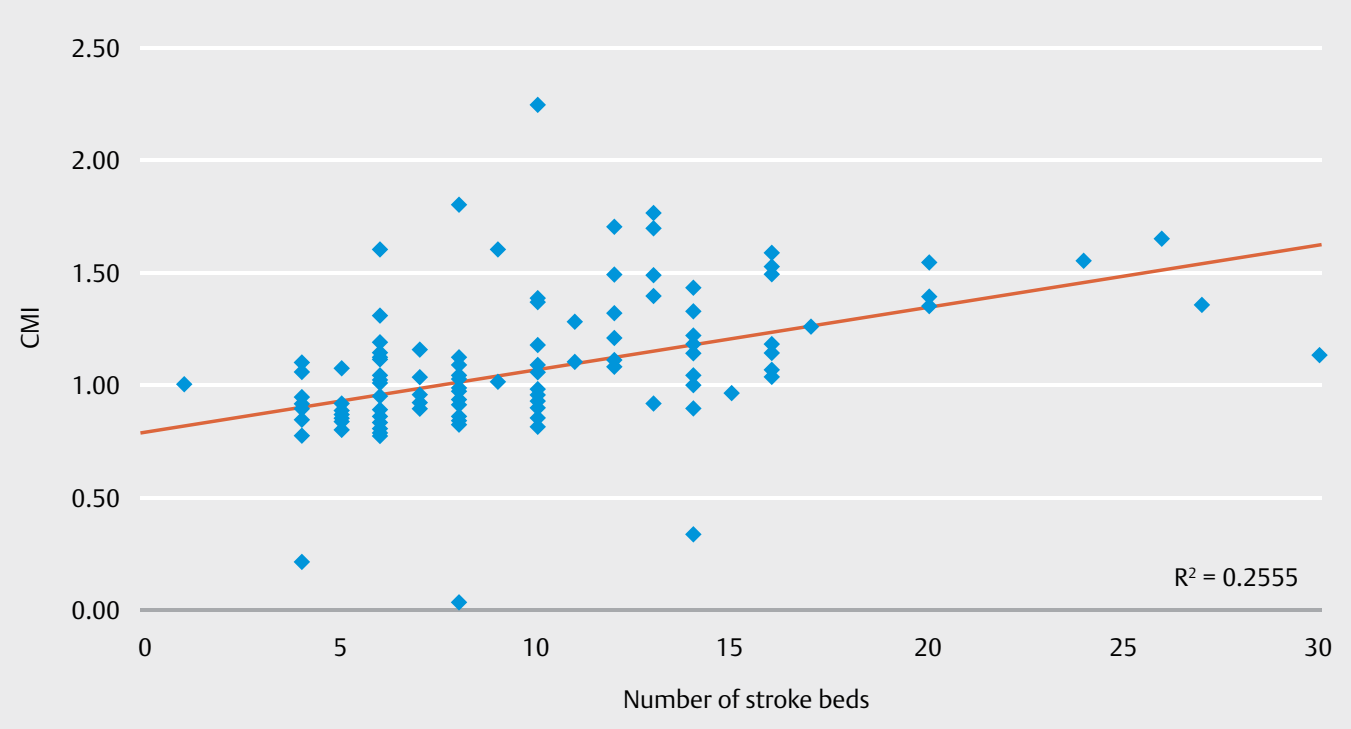

- Fig. 5 Number of stroke beds and CMI. There is not a strong correlation between the number of beds on the stroke unit and the average case severity (CMI) which accounts for the economic significance of stroke care for German neurologists.

Combination treatment of Parkinsonism was also frequently indicated as a form of complex treatment. Although the DRG system provides scope for the implementation and coding of complex treatment of other neurological diseases (e. g., epilepsy, multiple sclerosis, geriatrics), such combination treatments were absent except for individual cases.

Adequate personnel recruitment is a critical success factor for all hospitals. As in the preliminary surveys, we were unable to obtain a broad range of adjusted personnel numbers which would allow a differentiation among DRG-related tasks and other activities. The original idea was to query the percentage of revenue (\%) from the non-DRG area and then to distinguish an identical percentage share in the personnel budget. However, since only a minority of hospitals provided information, much of which appeared implausible, once again we have to report unadjusted personnel figures which relate - in unknown proportion - to non-DRG-related tasks. The range in the staffing key was correspondingly broad. The median was 16 full-time physicians with a staff key 1-4-11 (head physician - senior physicians - residents). Non-university facilities had a median position key of 1-4-11; university clinics reported 1-8-24.4. Whereas at non-university facilities, the mean ratio of head and senior physicians to residents was 0.44 (corresponding to one fulltime head or senior physician to 2.25 residents), at university-related facilities, this ratio was shifted toward the residents (median 0.375, thus approx. 1:2.7) > Fig. 6 .

On the whole, compared to 2013, somewhat more hospitals were affected by staff shortage and had to limit their care (2015: 29\%, 2013: $23 \%$ ). However, this was not due to the lack of physi- 


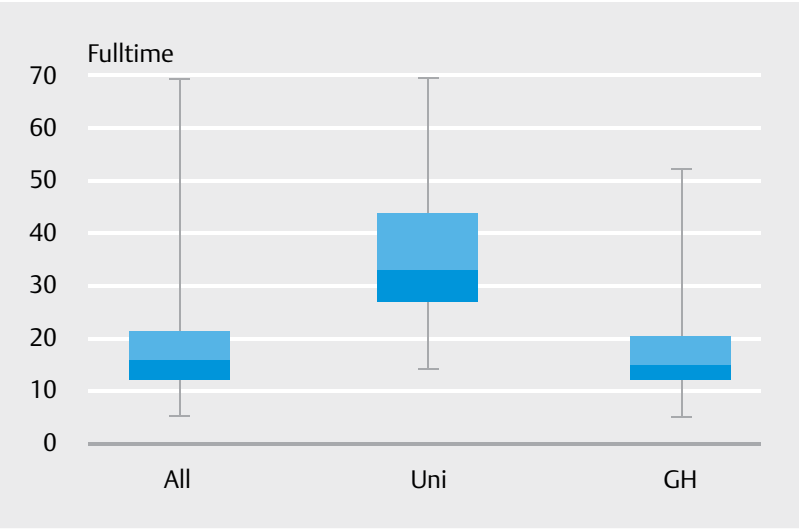

- Fig. 6 Full-time physicians. A Box and Whisper plot showed minimum, maximum, $25 \%$ and $75 \%$ quartile as well as median of total full-time staff in all hospitals (all), university-related facilities (Uni) and general hospitals $(\mathrm{GH})$.

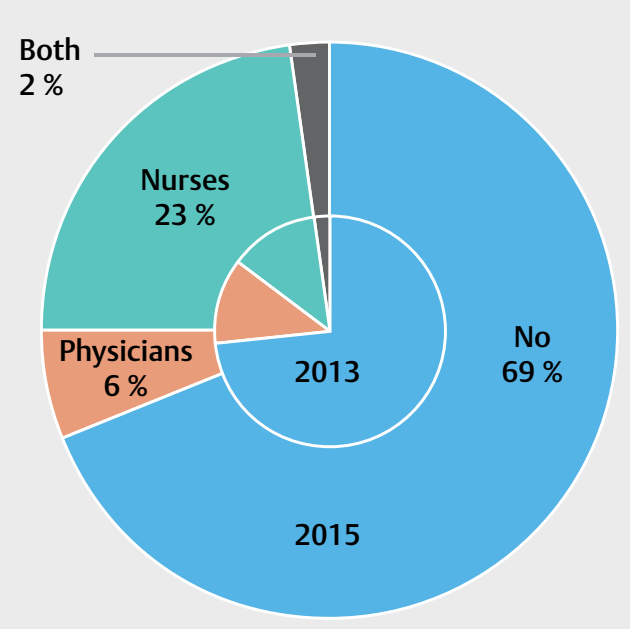

- Fig. 7 Staff shortage? Shortage of personnel resulting in reduction of care largely affected nursing - different from 2013. The small interior circle indicated the 2013; the large circle with indication of percent reflects 2015 responses.

cians, where the rate dropped from 12 to $6 \%$, but more than $22 \%$ of the hospitals were affected by a lack of nurses resulting in a temporary reduction of care. $\mathbf{F i g} .7$ illustrates these changes in personnel issues.

While a gender ratio of men to women of 1:1.5 was reported in the 2011 and 2013 polls, this time a nearly balanced gender relationship was reported, 1:1.02. Of the responding hospitals, 150 of 199 indicated reliance on part-time physicians. Consequently, the percentage rose from $70 \%$ in 2011 to $71 \%$ in 2013 to $75 \%$ in 2015 .

In previous years, hospitals were very skeptical regarding the question of whether certification processes for clinics lead to the improvement of care quality. In 2011 and 2013, almost exactly half of the hospitals had consistently denied that certification resulted in improvement in the quality of care, or such improvements were considered to be "not significant". There was a more optimistic assessment in the current survey. Of the respondents, $39 \%$ remain skeptical about these effects and deny any positive effects, or do not regard them as signif-
- Table 2 Proposals for measuring hospital quality.

\begin{tabular}{|l|l|}
\hline Category & Responses (greater than 1) \\
\hline Economic, routine data & $\begin{array}{l}\text { Readmission rate (10), increase in } \\
\text { cases (4), hospitalization time (2), } \\
\text { mortality (5), operating results (2) }\end{array}$ \\
\hline Physician personnel key (6), \\
\hline Physician-patient ratio (2)
\end{tabular}

Free text proposals were categorized, number of responses in parentheses. Parameters mentioned more than once are listed. Authors summarized similar responses

icant. However, $58 \%$ now see positive effects resulting from certification processes ( $3 \%$ of the respondents ticked more than one answer).

The stroke unit remained clearly at the center of the certification efforts. The stroke unit was not certified in 16 of 210 hospitals reporting stroke unit beds (7.6\%), thus representing 153 of the total 1924 reported stroke unit beds, i. e., $8 \%$. As in the preliminary surveys, we had formulated an open question about methods and means of quality assurance in the hospitals, which could be answered with free text. In contrast to the preliminary surveys, this question was well received this time, and numerous suggestions were made to measure results-oriented treatment quality in the hospitals. The responses were categorized and similar answers were grouped. $>$ Table 2 shows proposals that were submitted more than once. $>$ Fig. 8 presents the categories containing the responses. It is plain to see that the concept of quality is complex and mul- 


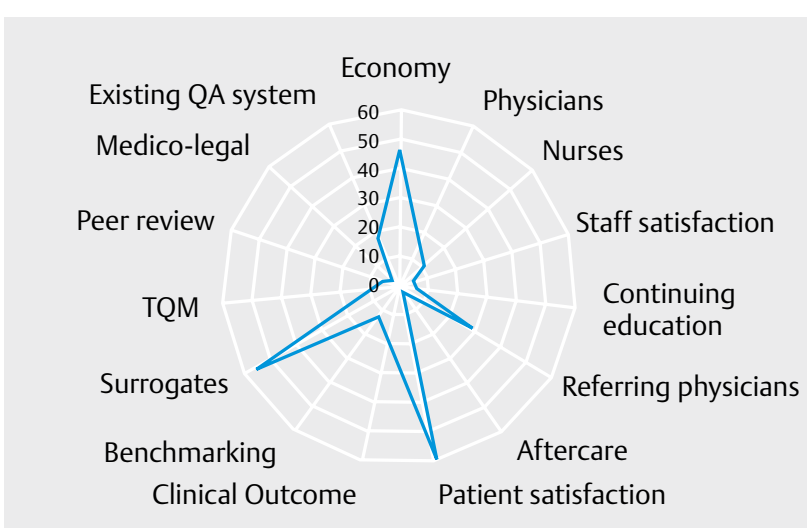

- Fig. 8 Proposals for measuring hospital quality. Breakdown of proposals by category (see text). The number of entries is shown. Hosp: Hospital, EMP: Employees, Pat: Patients, QA: Quality assurance, TQM: Total Quality Management.

tidimensional. Three colleagues suggested that such quality indicators do not exist; one suggested a scientific study.

\section{Discussion}

This is a report on the 12 th edition of the DGN survey of reference data for the 2015 reporting year. This survey continues to be highly accepted and, in comparison to similar surveys on a voluntary and free basis, receives a very high response rate. However, to achieve this, numerous mailings and repeated requests were needed. In addition, we accepted responses up to 6 months after the initial mailing. The questionnaire was kept deliberately brief; substantial consistency of the key questions ensured the comparability to the previous preliminary surveys [1-5]. Finally, in order to keep the threshold for the reply rate and the time required for the replies as low as possible, we again decided against digitization and consequent online survey, even though digital data collection would have sped up and simplified the evaluation.

When we examined the data, there were few hospitals reporting figures that represented extreme values (outliers). We have used the relevant internet information to obtain the specifics of these hospitals. Finally, in an effort to keep the study cohort as large as possible, we excluded only 6 hospitals from the evaluation, since it was obvious that the fig.s reflected a predominant business unit outside of the acute neurological hospital care area.

The evaluation followed the methodology of descriptive statistics. Formally we cannot demonstrate that the results follow a normal distribution or that the random sample is representative. In many areas, medians and quartiles are very stable compared to the preliminary surveys and, due to the size of the sample, they are also robust against extreme values. A good example of this is the number of beds, which was largely identical to the preliminary surveys. We also assume that valid comparisons are possible between the current and the preliminary surveys.

Since 2011, the number of hospitals with their own intensive care beds has decreased; consequently such hospitals are now in the minority. A significant consequence is that, in the area of intensive care, typical requirements of the continuing education rules can no longer be covered by neurological departments themselves [6].

The fact that, with one exception, all hospitals with a CMI greater than 1.22 had their own neurological intensive care beds suggests that the inclusion of intensive care beds in neurological departments also has important financial implications for the individual institutions. To what extent this affects the profitability of the individual hospitals cannot be assessed using the present data.

The inclusion of neurology as an emergency discipline in interdisciplinary emergency room structures is also a clear trend. In this case, neurological hospitals no longer predominantly rely on consulting physicians, but are served by on-call physicians. Stroke care is the predominant issue of neurological emergency services; this reflects the data of the TOP DRGs. The non-stroke DRGs include those patients with epileptic seizures and headache. Although the data do not permit a clearly quantifiable statement, the impression remains that the emergency admissions are increasing and elective admissions are decreasing more and more. Elective patients have to be taken care of in an outpatient setting. On the other hand, the emergency rooms are increasingly burdened by tasks which should actually be covered by (emergency) health care outside hopitals.

This development of "Neurology" as an emergency specialty is not always taken into account in the hospital infrastructure. Availability of a CT-angio is a given with few exceptions. Class 1 evidence is available for thrombectomy as a treatment for stroke in well selected patients [7]. If the necessary examination is not performed, a highly effective state-of-the-art therapy is withheld even for a portion of our stroke patients. After the publication of the MR CLEAN study in December 2014, the relevant required infrastructural measures would have been evident in the survey for 2015 [7]. Even more striking are infrastructure deficits with regard to the availability of MRI, as well as CSF diagnostics. In some hospitals, the data suggest a need for action, since improvement could not be measurably demonstrated when compared to identical survey questions in the most recent 2 preliminary surveys, even though depending on local circumstances different thresholds for the indication for an emergency MRI equipment might be underlie the "available" and "not available" responses. Likewise, the trend toward the orientation of inpatient care to emergencies will have an influence on further education in the neurology specialty. Important continuing education content will increasingly no longer be acquirable in the course of inpatient care. In order to continue to provide this subject matter it will be necessary to cooperate with outpatient care structures and to integrate them into the provision of continuing education. Innovative approaches in addition to empowerment, medical care centers, etc. further continuing education could inclusion of teaching practices.

In addition to infrastructure, staffing is always a central issue for the survey. With respect to the medical profession there is good news: the doctor shortage appears to on the decline, a balanced gender ratio appears to be achievable, $3 / 4$ of hospitals offer parttime models which is an indication of family-friendly working paradigms. It is indisputable, however, that there is still room for improvement in the management of neurology. In view of the increasing number of female staff, it is advisable that hospitals look for ways to retain qualified women in the long term. 
The case mix/physician ratio is likewise slightly declining, a possible indication of a slowdown of work intensification. An alternate explanation could be increased activity outside the DRG purview - outpatient care, consulting in outside clinics, participation in a medical care center or outpatient work at a hospital, examples of activities outside inpatient care compensated by DRG. Revenues outside the DRG system are generated by a variety of activities, only a few of which are identified here. These include elective services and private payment, income from rebated and rediscounted outpatient medicines, research, teaching, third-party projects, paid work for third-party institutions (e.g., consulting for other facilities) as well as services within the home institution which might not be apparent in internal billing procedures. There is a discrepancy in the reporting of many hospitals that indicate only limited revenue generated outside of the DRG area. It should be hoped that the survey is provides only a fragmented view of the revenue structures in the relevant departments. This is critical, since staffing is often calculated according to rules that are exclusively based on the DRG area and emergency services (for example DKI key fig.s, InEK key fig.s), but do not take into account the non-DRG area $[8,9]$. It is the responsibility of hospital managements to create the necessary transparency, as well as obtain support for necessary staffing requirements. The survey is still not able to provide generally valid benchmarks (see Box 1, Box 2).

\section{BOX 1: GERMAN AVERAGE NEUROLOGICAL DEPARTMENT}

- 56 beds, 8 of which are Stroke Unit beds, but there is no separate neurological ICU.

- Dispatches a physician to an interdisciplinary emergency room, at night at least on call.

- Has access to CT and CT angiography, while access to MRI 24/7 is limited or even absent.

- Apart from full inpatient care, it provides numerous services, e.g. in the outpatient area or (external) consulting. There is no transparency regarding costs with respect to additional (personnel) expenditure and revenues.

- The job code is 1-4-11.

- At least half the patients have a primary diagnosis of TIA or stroke.

- Emergency patients are predominant; the number of elective admissions is minor.

- Specialized combination treatments are not performed in significant number apart from complex treatment of acute strokes.

- Case mix 2700, CMI 1.08, average length of stay 5.4 days

- Revenue per bed/day 0.13 case mix points or approx. $420 €$ per bed and day.

- Revenue of 153 case mix points per physician per year (not adjusted by services outside the DRG area).

The situation is critical in the nursing area. If $22 \%$ of the hospitals indicate that they had to reduce their care due to a lack of nurs-
BOX 2: ESTIMATING ADDITIONAL PERSONNEL COSTS FOR NON-DRG SERVICES

Step 1: Services performed:

The Neurology Department in hospital A performs consulting services in hospital B. These are performed three times per week. An average of 10 consultations are performed per week. One consultation with documentation and travel time within hospital B takes 30 minutes. Travel time from hospital A to hospital B takes 30 minutes (one way). Calculation: 10 (consultations) x 52 (weeks) x 30 minutes $=15,600$ minutes and 52 weeks $\times 6$ trips $\times 30$ minutes $=$ 9,360 minutes, thus for physician expenditure: $24,960 \mathrm{~min}$ utes/year.

Step 2: Actual annual working timeof a physician at hospital A:

Of 52 weeks there are 6 weeks of vacation; 1.5 weeks of legal holidays; one week of paid time off for continuing education, thus 43.5 weeks remaining. At a sickness absence rate of $8 \%$ in the medical service of hospital $A$, an additional 3.5 weeks of absence time ( $8 \%$ of 43.5 weeks) should be planned. Remaining are 40 weeks actual working time, each of 42 hours $x 60$ minutes, corresponding to 2520 minutes/week, thus 100,800 minutes/year as annual working time.

Step 3: Calculation of additional full-time personnel requirements for providing consultation at hospital B:

Expenditure for physicians (minutes)/ annual working time per full-time position, therefore $24,960 / 100,800=0.25$ full-time.

ing staff in 2015, it has to be assumed that there is a widespread shortage of nurses in neurological hospitals. Although this is not a neurology-specific problem, the task for the neurological professional association, as well as for each department, is to attract, nurture and retain nurses to support neurology. The board of the DGN has already focused on this information from the survey and has set up a task force for nursing in neurology. This also reflects the importance of this survey and shows that participation is worthwhile.

On the whole, interest focus on economic data: case mix, case mix index and number of cases. The preliminary surveys already identified a downward spiral, the tendency to increase the number of cases and reduction of hospitalization time in the face of declining per case values. The current survey confirms this long-term DRG-inherent trend, with a further acceleration of the decrease in the length of hospitalization time with a median of 7.3 reduced to 5.4 days. Once again this exceeds the average trend in all disciplines in German hospitals, where the duration of the stay from 2013 to 2015 decreased only from 7.5 to 7.3 days [10].

Comments on the preliminary surveys have stated unanimously that the absolute lower limit of the length of stay had already been reached, and that a continued decrease was a cause for concern regarding a decline in care quality. If this is taken seriously, then an additional $17 \%$ reduction in hospitalization time in 2 years 
would make a decline of quality clearly apparent. This leads directly to the issue of how quality and quality deficiencies should be measured. This question is the subject of current health policy discussions and remains largely unanswered by the neurological profession. With this quality discussion in mind, we asked how result-oriented quality might be measured. The responses to this were many-faceted and characterized the complexity of the quality concept for health care. Fig. 8 illustrates the relevant dimensions of the evolving quality concept. Economic parameters, surrogates (in particular the "door to needle time" in stroke care) and parameters directly related to patient satisfaction are considered the most significant measures of a high level of care quality.

The proposals presented here could provide impetus for a discussion of quality which would supplement or replace process-oriented quality indicators in the certification criteria.

In summary, we were able to gain valuable information and benchmarks for German neurological hospitals responsible for acute care, and make this available to the public. The primary areas of action particularly included a) infrastructural shortcomings, b) personnel shortage in nursing and c) defining results-oriented quality criteria in a time of accelerating reduction of hospitalization time. Indirectly, there were indications for a lack of cost and revenue transparency as well as their differentiation for non-DRG services in the hospitals. In the previous surveys we refrained from collecting parameters such as per patient and cost unit accountings a) since these are not established in all hospitals, b) factors such as internal cost allocation which have significant influence on the cost unit accounting, but are handled differently, and c) since the extent of acceptance is unknown regarding transmission of this sensitive data. At this point, however, it should be pointed out that hospital administrations, for example, have long been exchanging a wide range of data and intensively benchmarking them for companies and hospital groups, including personal performance indicators for all important achievement parameters. It is not only desirable, but also a prerequisite for hospital clinicians to be involved in these processes so that in the future neurological hospitals will be able to successfully fulfill their important clinical care mission according to the state of current science while respecting all aspects of human medicine.
Conflict of Interest

No conflict of interest has been declared by the authors.

\section{References}

[1] Wallesch CW, Brand T, Engelhardt A et al. Ergebnisse der 7. Erhebung zur Struktur der neurologischen Kliniken der Akutversorgung in Deutschland. Akt Neurol 2005; 32: 155-161

[2] Wallesch CW, Brand T, Engelhardt A et al. Ergebnisse der 8. Erhebung zur Struktur der neurologischen Kliniken der Akutversorgung in Deutschland. Akt Neurol 2008; 35: 359-369

[3] Wallesch CW, Fink GR, Engelhardt A et al. Ergebnisse der 9. Erhebung zur Struktur der neurologischen Kliniken der Akutversorgung in Deutschland. Akt Neurol 2011; 38: 1-11

[4] Schroeter M, Engelhardt A, Erbguth Fj et al. Ergebnisse der 10. Erhebung zur Struktur der neurologischen Kliniken der Akutversorgung in Deutschland. Akt Neurol 2013; 40: 1-10

[5] Schroeter M, Lüßem B, Engelhardt A et al. Ergebnisse der 11. Erhebung der Deutschen Gesellschaft für Neurologie zur Struktur der neurologischen Kliniken der Akutversorgung in Deutschland. Akt Neurol 2015; 42: 72-79

[6] http://www.bundesaerztekammer.de/fileadmin/user_upload/ downloads/pdf-Ordner/Weiterbildung/MWBO.pdf Accessed January 17, 2017

[7] Berkhemer OA, Fransen PS, Beumer D et al. A randomized trial of intraarterial treatment for acute ischemic stroke. N Engl J Med 2015; 372: $11-20$

[8] Frieling M, Beck U, Becker A. Personalkennzahlen als Instrument der Unternehmenssteuerung. das Krankenhaus 01/2008, S 45.-50. Kohlhammer; Stuttgart: 2008

[9] www.g-drg.de/cms/inek_site_de/.../1/.../Abschlussbericht_ G-DRG-System2014.pdf Last access January 17, 2017

[10] https://www.destatis.de/DE/ZahlenFakten/GesellschaftStaat/ Gesundheit/Krankenhaeuser/Tabellen/KrankenhaeuserjahreOh ne100000.html Last access January 17, 2017 